University of Nebraska - Lincoln

DigitalCommons@University of Nebraska - Lincoln

Faculty Publications: Department of Teaching, Department of Teaching, Learning and Teacher Learning and Teacher Education

Education

2008

\title{
Multicultural Education: Raj's Story Using a Curricular Conceptual Lens of the Particular
}

Vicki Ross

Elaine Chan

Follow this and additional works at: https://digitalcommons.unl.edu/teachlearnfacpub

Part of the Curriculum and Instruction Commons, and the Teacher Education and Professional

Development Commons

This Article is brought to you for free and open access by the Department of Teaching, Learning and Teacher Education at DigitalCommons@University of Nebraska - Lincoln. It has been accepted for inclusion in Faculty Publications: Department of Teaching, Learning and Teacher Education by an authorized administrator of DigitalCommons@University of Nebraska - Lincoln. 


\title{
Multicultural Education: Raj's Story Using a Curricular Conceptual Lens of the Particular
}

\author{
Vicki Ross ${ }^{1}$ and Elaine Chan ${ }^{2}$
}

1. Department of Teaching and Learning, College of Education, Northern Arizona University, Flagstaff, Arizona, USA

2. Department of Teaching, Learning, and Teacher Education, College of Education and Human Sciences, University of Nebraska-Lincoln, Lincoln, Nebraska, USA

Corresponding author - Vicki Ross, Department of Teaching and Learning, College of Education, Office 207J, Education Building, P.O. Box 5774, Northern Arizona University, Flagstaff, AZ 86011-5774, USA; telephone 928-5237194; email vicki.ross@nau.edu.

Reach Elaine Chan at Department of Teaching, Learning, and Teacher Education, College of Education and Human Sciences, 24 Henzlik Hall, P.O. Box 880355, University of Nebraska-Lincoln, Lincoln, NE 68588-0355, USA; telephone 402-472-6169; email echan2@unl.edu

\begin{abstract}
In this study, we employ a curricular conceptual lens of the particular to explore the experience of multicultural education from the perspective of an immigrant student, Raj. Using a school-based narrative inquiry approach, we learn about Raj's experiences at the intersections of immigration and settlement, adaptation and assimilation, English-language acquisition, unemployment, poverty, family violence, and family relocation. We employ Dewey's [(1938). Experience and education. New York: Simon \& Schuster] theory of experience, Connelly and Clandinin's [(1988). Teachers as curriculum planners: Narratives of experience. New York: Teachers College Press, Columbia] understanding of curriculum as experience, and Schwab's [(1969). The practical: A language for curriculum. School Review, 78, 1-23] theory of the particular as theoretical frameworks upon which to examine and analyze interactions and events.
\end{abstract}

Keywords: teacher education (learning to teach in inner city schools with diverse populationsLTICS), multicultural education (respecting ethnic and cultural heritage-REACH), curriculum, narrative inquiry 


\section{Introduction: Who is Raj?}

I was sitting with Raj and Dean in Room 42 today, helping them complete the ESL Survey. As I asked them about their English and home language use and their educational history, the story of Raj and his family began to unfold. In response to the survey question on ESL status, Raj indicated that he is not "in ESL." ${ }^{1}$ He added, "but my sister is [in ESL]." I've known Raj since the beginning of the school year, and his English is fluent, native-like even. I was puzzled that his sister would be in ESL since I didn't think the family was among those who had arrived in Canada recently. I wondered, Is it possible that Raj's family had only recently arrived and that he had achieved native-like fluency so quickly? When I asked Raj about his sister, he explained, “Me, my brother, and my little brother - not the littlest one because he was born in Canada but the other brothercame at the same time. My sister stayed with my grandfather and grandmother in Sri Lanka so the army wouldn't get suspicious. She came to Canada after us, so she couldn't speak English. She had to go to ESL." Raj then described how his family slipped away in the dark one night, leaving his birth country to settle in Canada 2 years before his younger sister was able to join them. (Field note, spring 2001)

This field note records an interaction between Liz and two eighth-grade students from the middle school section of Bay Street School. This excerpt introduces our inquiry into multicultural education and how it may be experienced by students in a diverse, urban school setting. While the question about his sister's ESL status seems relatively straightforward, Raj's response hints at complexities important to the multicultural education conversation informing educators, administrators, and policymakers about the kinds of experiences students of minority background bring to a school context. We use a curricular lens of "the particular" (Schwab, 1969, 1978, p. 309) in relation to Schwab's $(1973,1978)$ curriculum commonplaces to explore the interaction of language acquisition, immigration and settlement, family relocation, parental unemployment, and family violence-complex issues that may impact the academic success of immigrant students. At the same time, we trace policy responses to Raj and his siblings' academic, social, and language needs in a multidimensional context of home, school, and community.

\section{Theoretical framework and purposes of the study}

We are concerned with the experience of the child and the family, the understanding of teachers and the school context (Connelly \& Clandinin, 1988, 1994), the role of the community, and, finally, national identity considerations (Dewey, 1916), all of which are rooted in Dewey's (1938) philosophy of experience. Taken together with Dewey's (1938) conceptualization of education and experience, Connelly and Clandinin's (1988) notion of curriculum linked to "life course" (p. 11) - as what we do, why we do it, and what our intentions are for the future-grounds our inquiry into the story of one student and his family. Clandinin and Connelly (1992) state, 
Teachers and students live out a curriculum; teachers do not transmit, implement, or teach a curriculum and objectives; nor are they and their students carried forward in their work and studies by a curriculum of textbooks and content, instructional methodologies, and intentions. An account of teachers' and students' lives over time is the curriculum, although intentionality, objectives, and curriculum materials do play a part of it. (p. 365)

This conceptualization of curriculum as teachers' and students' lives over time, as presented above, focuses our attention on the importance of examining curriculum as experienced by one child. In this examination of Raj's experience as a student in a diverse school setting, we connect a conceptualization of curriculum to students' and teachers' lives over time, as situated and lived in the particular. This view of curriculum originates with Schwab's $(1973,1978)$ curriculum commonplaces. Schwab argues that four commonplaces must be recognized in a defensible curriculum process: the teacher, the learner, the subject matter, and the milieu. The commonplaces allow us to think both holistically and particularly about the curriculum.

Schwab $(1969,1978)$ argues that it is the particular that is at the heart of teaching practice. In The Practical: A Language for Curriculum, Schwab $(1971,1978)$ states, "Questions of what and how to teach arise in concrete situations loaded with concrete particulars of time, place, person, and circumstance" (p. 322). Whereas particulars are absent, subtracted, and dismissed in theory, Schwab views curriculum as a fundamentally practical, rather than theoretical, undertaking.

Having explained the conceptual framework structuring this inquiry, we delineate the purpose and create an overview of the text. We ground our inquiry in the concrete curriculum of multicultural education and explore particular assertions sometimes presented in formalistic statements about the needs of students of ethnic communities. Using a narrative inquiry approach (Clandinin \& Connelly, 1994, 2000), we explore experiential aspects (Dewey, 1938) of multicultural education. To this end, we describe the particulars (Schwab, $1969,1978)$ by telling the story of Raj, an eighth-grade student in Room 42 at Bay Street School. From this telling, we foreground complexities and issues arising in this child's experience of multicultural education. The particulars of such a curriculum highlight topics from multiple perspectives.

\section{Multicultural education as curriculum: particular assertions, selected matters}

At the outset, we acknowledge that the importance of recognizing students' diversity in school contexts is supported in multicultural education research. Moodley (1995) affirms the need for "information and awareness of the cultural backgrounds of pupils in order better to diagnose strengths, weaknesses, and differences in cognitive styles" (p. 817). Banks (1995) emphasizes the inclusion of culture in the curriculum as a means of helping students develop positive racial attitudes. There is an abundance of research highlighting the need for culturally relevant pedagogy (Ladson-Billings, 1995, 2001; Villegas, 1991) and culturally responsive teaching (Gay, 2000) that builds upon experiences and knowledge that students of ethnic minority background already possess. Ada (1988), McCaleb (1994), 
Igoa (1995), and Cummins $(1996,2001)$ stress the importance of acknowledging the cultural knowledge that students of diverse ethnic and linguistic backgrounds bring to classroom and school contexts. McCaleb (1994) and Cummins (1996) elaborate upon dangers of failing to recognize the value of cultural knowledge in a school context. Rodriguez (1982), Wong-Fillmore (1991), and Kouritzin (1999) present accounts of ways the failure to support maternal language maintenance and development for students of ethnic minority background impacted their ethnic identity and sense of belonging in their families and ethnic communities.

Overall, the personal, professional, and societal benefits of welcoming diverse cultures and languages into school contexts are well documented in multicultural education research literature and policies governing school practices. Less adequately addressed in this literature are experiential accounts of multicultural education and documentation of ways ethnic minority students experience school, home, and neighborhood lives. Examples of this more experiential approach do exist, however, and this research continues a growing tradition of narrative-based explorations of immigrant and minority student lives in their schools (Carger, 1996; Chan, 2006, 2007; Huber, Murphy, \& Clandinin, 2003; Huber \& Whelan, 2001; Phillion, He, \& Connelly, 2005).

We describe Raj's experience in a particular locus in time and space, beginning with a description of his eighth-grade classroom-not an archetypical classroom, but Room 42, where Raj spent a good portion of each school day. This description precedes a detailing of the school context. We then create a characterization of the immediate school community, which has much to do with what is achieved at Bay Street School and in Room 42. Upon creating a context of understanding, we return not to a generic child, but to Raj and our exploration of his experience of multicultural education. Following, we provide a broader view outlining school board and Ministry of Education policies, and, finally, the national agenda in Canada around aspects of multiculturalism are presented.

\section{Methodology: Gathering information about Bay Street School}

This examination of the particular emerges from a 3-year study situated in the middle school of Bay Street School. We first met Raj when we spent time in his classroom as participant observers as part of a long-term, school-based research project. In Life in the Classroom, first published in 1968, Jackson (1990) promotes and predicts observational studies within and of classrooms coming to play an increasingly informative role in education research. He argues for the value of observation with "an open mind," unconstricted by what "should be going on" or even by the "logical link between the abstract processes of teaching and learning" (p. 176). Craig (1995, 2003a, 2003b, 2003c, 2004, 2006a, 2006b) embraces this spirit in her work; her descriptions of events in classrooms with teachers and children exemplify Jackson's exhortation to understand life in classrooms. Growing out of the narrative inquiry tradition and grounded in the work of Clandinin and Connelly (1988, 1994, 2000), she explores the lives and contexts of teachers and students. Likewise, Ross (2003, 2004) uses this line of research to explore issues of curriculum, and Chan $(2006,2007)$ relies on narrative inquiry to investigate diversity in schools, families, and communities. He, Phillion, and Roberge (1999) further substantiate the value of long-term participant 
observations often used by narrative inquirers, stating, "By being up-close to lives and intimately involved in the daily storied lives of the participants, narrative inquirers develop an understanding of the complexity of people's changing lives"' (p. 454).

To learn about the intersection of ethnicity, culture, and curriculum at Bay Street School, we took part in school events and activities such as Multicultural Night, Curriculum Night, School Council meetings, staff meetings, and field trips and attended such special school events as band concerts, music performances, and celebrations. During the 2000-2001 school year, Raj was a student in the eighth-grade classroom where Elaine was conducting research on the ethnic identity of first-generation Canadian students.

We recorded extensive field notes following each school visit, classroom observation, interview, and conversation with members of the school community. All information was filed into an archival system. Field notes written about Raj for this study were set into a historical context of the school community dating back more than 25 years, when the research project first began in the school.We also collected newspaper articles, school board documents, videos of school and classroom events, samples of student work, and correspondence between teachers, administrators, and the families of the students to further inform our understanding of diversity in school communities in the Toronto area.

Raj's homeroom consisted of 38 eighth-grade students, including students requiring special education and those who spent a part of their school day in the ESL Reception Class. The two eighth-grade homeroom classrooms in the school occupied the oldest part of the building, referred to as "the tower" by teachers and students. The students moved back and forth between Room 42 and Room 47 according to their schedule, leaving these two classrooms only for specialized subjects such as Physical and Health Education, Art, French, and Music. Raj took Math, Science, and Geography from his homeroom teacher, Mr. James Rudman, in Room 42, while the other eighth-grade homeroom teacher, Mr. William Jisko, taught History, Language Arts, Design and Technology, and Family Studies to the same two groups of students in Room 47. The two homeroom teachers, along with an education assistant and their group of 76 students, formed a "pod," moving through seventh and eighth grades together as a group.

\section{A particular locus in time and space}

The curriculum constructed of these particulars will be brought to bear, not in some archetypical classroom but in a particular locus in time and space with smells, shadows, seats, and conditions outside its walls which may have much to do with what is achieved inside. (Schwab, 1969, 1978, p. 309)

Schwab's $(1969,1978)$ description of curriculum as constructed of particulars highlights the importance of contextual factors shaping the development and implementation of curriculum. We describe in further detail the neighborhood and community context where Raj and his siblings attended school. Toronto has been identified by the United Nations (United Nations Development Programme, 2004b) as one of the most multicultural cities in the world, second only to Miami, Florida, in terms of the percentage of foreign-born population. Nearly half of the population of Toronto (42\%) was born outside Canada 
(United Nations Development Programme, 2004a), and as much as $11.2 \%$ of the population identified themselves as members of a visible minority group (Statistics Canada, 1998). Furthermore, the linguistic, racial, and ethnic composition of the city (Statistics Canada, 2001, 2003b) continues to become increasingly diverse (Statistics Canada, 2003a).

The neighborhood in which Bay Street School is located is highly diverse, and has been home to new immigrants in Toronto for generations (Connelly, He, Phillion, Chan, \& Xu, 2004; Connelly, Phillion, \& He, 2003). As each successive wave of immigration washes up on the shore, people settle, build, and move on, leaving behind traces of their presence. As an example, Victorian buildings lining both sides of the streets are faced with signs in Vietnamese and Chinese to reflect the ethnic composition of the current neighborhood community, and in Portuguese to reflect their strong presence in previous decades.

The original old brick and stone school building was built at the end of the 1870s along a busy street lined with shops and independent merchants. Constructed of large, red stone, the school building has tall, narrow windows spanning the length of the wall on each floor. These windows look out the south side of the building. The newer part of the building is perpendicular to the original building; this part runs north toward the major roadway, with windows facing east and west.

The conversation recorded in the introductory field note occurred in Room 42, a large classroom where Raj began and ended each school day. The room was originally a northfacing Family Studies room with four compact kitchens and a large, open area with rectangular tables where earlier generations of students learned cooking and sewing skills. Since the fall of 2000, when Elaine began working with this group, Raj's eighth-grade teachers had used the kitchen area only once for a Family Studies lesson and once for the preparation of food for the International Foods Fair. Usually Mr. Rudman had the students use the blackboard and desk area of the classroom for their Geography, History, and Math lessons. On this particular spring day toward the end of the school year, Raj and his classmates were scattered at tables around the room in small groups of two or three working on Health and Guidance assignments requiring collaboration. Elaine took this opportunity to complete ESL surveys with individual students who had not yet submitted them.

In our role as school-based, narrative inquiry researchers, we worked in classrooms with teachers and their students and assumed schoolwide and community undertakings as well. The fluidity of our roles as narrative inquirers is illustrated in the nature of our work with our participants. We approached our work with a sense of commitment and responsibility to assist the teachers and administrators with whom we worked in whatever ways we were able. This principle originated with Clandinin's work with her research participant, Stephanie, at Bay Street School in the 1980s (Clandinin, 1986), was explored in Clandinin and Connelly's (2000) writing and in their work with students, and has, for decades, guided the work of researchers on the Bay Street School project. Craig and Ross (2007) link this approach to Schwab's (1969) notion of the practical and bring to our attention the significance of teachers and professors of education (curriculum) working and learning together in public schools. Our work as school-based narrative inquirers was in line with Clandinin and Connelly's (2000) notion of the critical role of researchers "making ourselves useful in whatever ways we could" (p. 71) to our teacher and student participants. The seemingly unusual participation of narrative inquirers in the very quantitative 
task of developing and analyzing a survey is an example of narrative inquiry researchers contributing to the school community.

As we worked with Raj and his classmate, Dean, to complete the surveys, they related stories of immigration and challenges of communicating with peers and parents. This new knowledge deepened existing knowledge we had acquired through interaction with their teachers and information we gleaned through working directly with the students in their school and classroom context. The "big-picture" information about social context gained through the quantitative survey complemented information gathered through qualitative long-term participant observations and conversations to enrich our overall understanding of the students; these stories provided the social narratives, the nuances that set the backdrop for what we observed and learned in the school context.

The fluidity of our role as narrative inquirers was apparent in this research as we reflected upon the nature of collaborative work with members of the school community over the years of our involvement, and in particular, in this instance of collaboration with members of the ESL Workgroup. More specifically, teachers of the ESL Workgroup at Bay Street School initiated a schoolwide survey to investigate the maternal language use and educational histories of their students. Collectively, they had an intuitive sense that policies established to meet the needs of earlier immigrant populations were not meeting the needs of more recent groups of students. Participant observations with our teacher participants in their classrooms extended to accompanying and assisting them with various responsibilities and commitments around the school community, including participation in professional interests such as collaboration with colleagues in the ESL Workgroup. Gradually, our interest in and support of the work of the teachers grew into active participation as we assisted teachers with the development and administration of the survey instrument and follow-up analysis of the data. In our analysis of what we knew about the students, we embedded the quantitative descriptive data gathered from the ESL survey into data gathered from a 25-year program of research based at the school. This seemingly tangential work of developing a quantitative ESL survey from which statistics about the ethnic composition of students at the school were drawn was embedded into a long-term narrative inquiry with qualitative roots beginning in the early 1980s. In fact, our involvement in the ESL survey grew out of and was possible due to the fluidity of our roles as narrative inquirers and our long-term participation at the school.

Knowledge gained about our teacher and student participants through this ongoing interaction was, in turn, set into the context of regular contact with the school principal to learn about his goals for building a school community, knowledge of school board policies, social and political context shaping interactions and activities in the school and neighboring community, and specific family and classroom influences shaping the experiences of individual students and teachers. Our involvement in helping to develop, implement, and analyze the results of a quantitative all-student survey grew out of our long-term commitment to working with our teacher participants to learn about influences on the academic growth of their students. Likewise, our work in the school and with administrators allowed us to see the tensions emerging for them on the school landscape. Teachers felt and dealt with these tensions; in fact, these tensions were the impetus of this survey. 
The survey was a means for teachers in the ESL study group to adopt what they perceived as a language of administration. The numerical representation, they felt, would be received more readily than teachers' stories of students' struggles. Multicultural policies are often formed on the bases of quantitative or large-scale surveys, but as illustrated in this study, it is the particular lives of individual students in the midst of these policies that need to be considered. Until these particular lives are considered, there is little chance of meaningful or sustained change in schools or society as we attempt to support the success of immigrant and minority students. Teachers with whom we worked understood the importance of these stories but needed a means of expressing this knowledge in ways that would be convincing to policymakers.

Meanwhile, administrators in the school experienced other tensions while acting within the constraints of board expectations. For example, in this same period of time in which teachers were voicing that the needs of students were not being met, plans were afoot at the board level to cut funding for International Language programs at Bay Street School due to funding shifts at the provincial and ministry levels. School administrators were left to balance the needs and power bases of different parent groups, none of which wanted to see their language instruction cut from the curriculum. These school administrators themselves held deep convictions about the enriching nature of diversity at Bay Street School. Outside the school, there was the tension of the board trying to manage funding and the pulls and pushes of a movement toward greater accountability and standardization expressed within social narratives at large.

\section{A particular student: Learning about Raj's story of immigration and settlement}

Above all, the supposed beneficiary is not the generic child, not even a class or kind of child out of the psychological or sociological literature pertaining to the child. The beneficiary will consist of very local kinds of children and, within the local kinds, individual children. (Schwab, 1969, 1978, p. 309)

As illustrated in results of the "(Every Student) ESL Survey" (Chan \& Ross, 2002), administered to the students during the 2000-2001 school year, the ethnic composition of students at the school was highly diverse (Fig. 1). Students spoke 31 languages (Fig. 2) and represented 38 countries (Fig. 1). A breakdown of the ethnic backgrounds of students in Raj's homeroom classroom further confirms the extent of diversity (Fig. 3). 
Ross AND CHAN, TEACHING AND TEACHER EDUCATION 24 (2008)

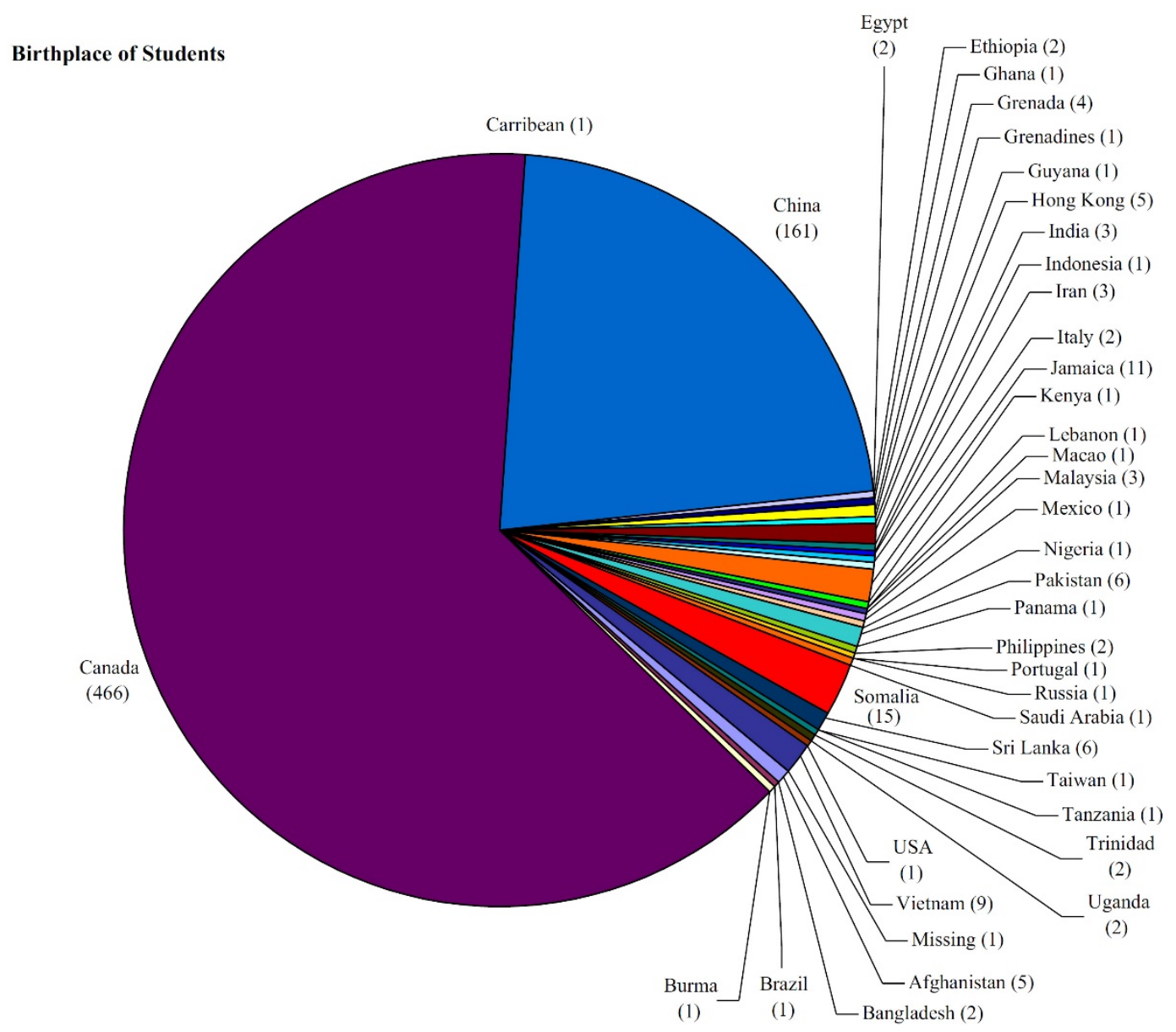

Figure 1. Birthplace of students 


\begin{tabular}{|c|c|c|c|}
\hline \multicolumn{4}{|c|}{ Languages Spoken by Students } \\
\hline & Inside Canada & Outside Canada & Total for each language \\
\hline Arabic & 35 & 15 & 50 \\
\hline Bangla & 3 & 0 & 3 \\
\hline Bengali & 4 & 3 & 7 \\
\hline Cambodian & 1 & 0 & 1 \\
\hline Cantonese & 47 & 34 & 81 \\
\hline Chinese & 136 & 157 & 293 \\
\hline English & 333 & 181 & 514 \\
\hline Farsi & 2 & 0 & 2 \\
\hline French & 64 & 60 & 124 \\
\hline Fujianese & 0 & 13 & 13 \\
\hline German & 1 & 0 & 1 \\
\hline Italian & 1 & 1 & 2 \\
\hline Korean & 3 & 0 & 3 \\
\hline Laotian & 1 & 0 & 1 \\
\hline Mandarin & 17 & 54 & 71 \\
\hline Persian & 6 & 4 & 10 \\
\hline Portuguese & 14 & 3 & 17 \\
\hline Punjabi & 0 & 2 & 2 \\
\hline Pushto & 8 & 3 & 11 \\
\hline Russian & 0 & 1 & 1 \\
\hline Somali & 32 & 13 & 45 \\
\hline Spanish & 33 & 7 & 40 \\
\hline Swahili & 10 & 5 & 15 \\
\hline Tamil & 1 & 6 & 7 \\
\hline Telugu & 0 & 1 & 1 \\
\hline Thai & 1 & 0 & 1 \\
\hline Tigrina & 3 & 1 & 4 \\
\hline$T w i$ & 1 & 0 & 1 \\
\hline Urdu & 3 & 4 & 7 \\
\hline Vietnamese & 81 & 12 & 93 \\
\hline Yoruba & 0 & 1 & 1 \\
\hline TOTAL & 841 & 581 & 1422 \\
\hline $\begin{array}{c}\text { \# of Different } \\
\text { Languages }\end{array}$ & 26 & 23 & 31 \\
\hline
\end{tabular}

Figure 2. Languages spoken by students 


\section{Birthplace of Students in Rm. 42 \\ (Elaine Chan)}

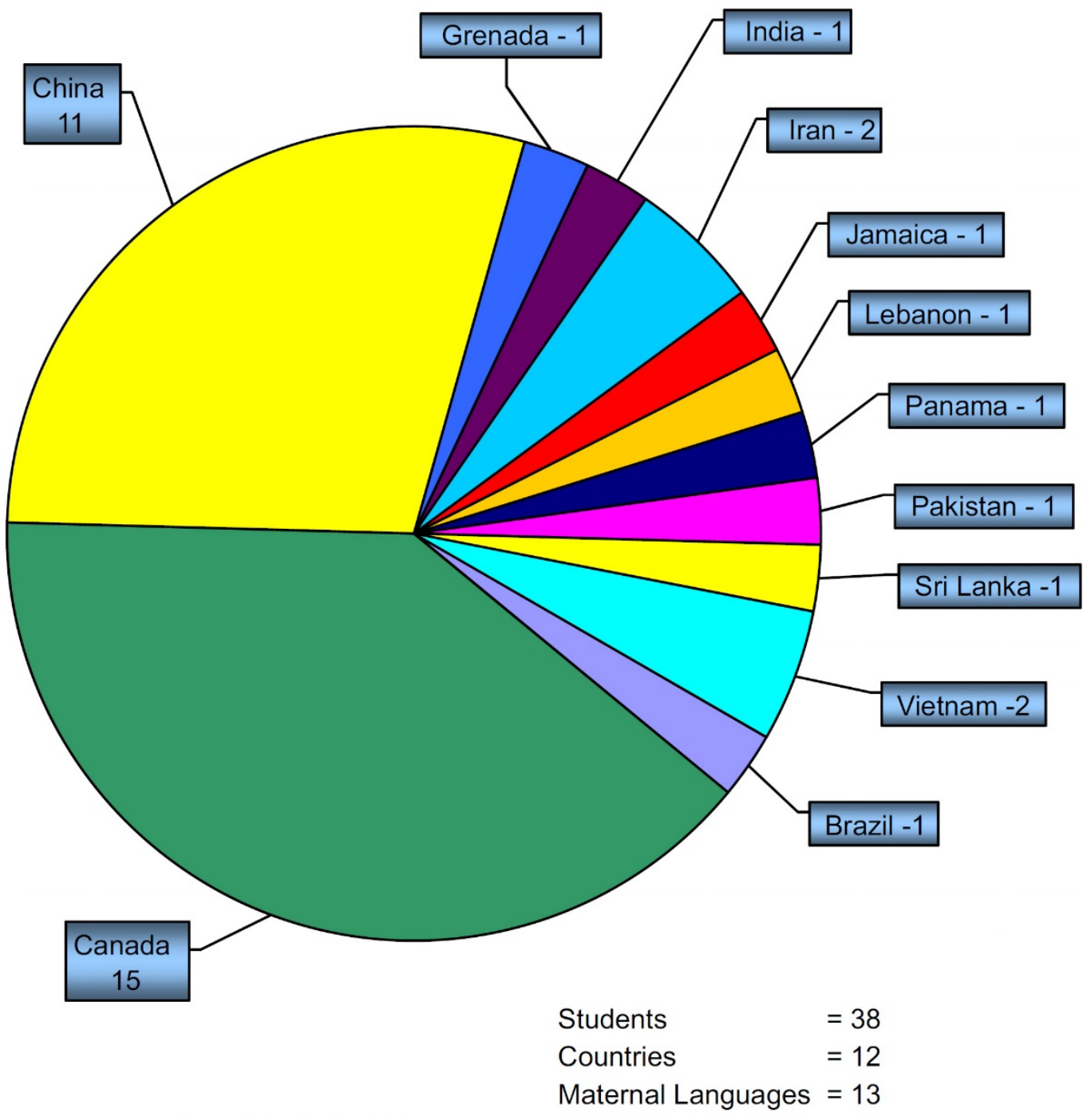

As of April 18, 2001

Figure 3. Birthplace of students in Room 42 (Elaine Chan)

As illustrated in Figures 1-3, Raj and his peers at Bay Street School were a diverse group. In Figure 3, one child responded that he or she was born in Sri Lanka. This sliver of the pie chart represents Raj. So easily, in this type of representation, Raj could slip into the "generic" (Schwab, 1969, 1978, p. 310) child portrayed in the multicultural education literature. Indeed, we believe narrative methodology allows us to introduce the particulars of Raj's experience into this curriculum discussion by highlighting details of his life that 
inform the reader of the nuances and complexities of his day-to-day transition from his home to school.

To begin with, the data illustrate pronounced diversity at Bay Street School. Of the 38 eighth-grade students in Raj's homeroom, 11 named China and 2 indicated Vietnam as their birthplace, for a total of 13 of 38 students immigrating to Canada from Asia. From the Middle East, Raj named Sri Lanka as his country of birth, while five of his classmates listed Pakistan, Lebanon, India, or Iran. Four students were from Latin America or the Caribbean, with one student each from Grenada, Jamaica, Panama, and Brazil. Although 15 students specified Canada as their birthplace, what is not evident in their survey responses is the number of students who were born in Canada into families of ethnic minority background or are second-generation immigrants.

The data from Figure 3 hint at the remarkable diversity in one classroom, but they do not tell the details of the stories of immigration and resettlement lived by 23 of the 38 students in Raj's homeroom, nor do they shed light on the immigration stories of individual students emanating from 11 countries. For example, by the age of 14, most of Raj's classmates had been displaced at least once as they moved from their countries of birth to settle in Canada, and many more were uprooted multiple times as their families moved into and resettled out of this transient neighborhood. The nuances of these complexities of (re)settlement can be presented and explored in the rich detail in which they were lived through examination of stories such as those experienced by Raj and his family members. Based on field notes written over the course of the year (September 2000-June 2001) as we took part in day-to-day life in Bay Street School, we are able to piece together some of the details of the "second-hand stitched together stories" (Clandinin et al., 2006) of Raj's life through interactions with his teachers, parents, and peers and directly with him.

To begin with, Raj lived with his brothers, sister, and parents across the street from Bay Street School in a home above the convenience store his parents ran. When Elaine commented on Raj's native-like fluency in English and contrasted it to his sister's ESL status, his homeroom teacher, Mr. Jisko, responded that Raj, however, had not "done a stitch of [written] work in months" (field notes, May 2001). At the time when the introductory field note was written, Raj and his family were uncertain about the future as they struggled to come to terms with their father's psychological difficulties, thought to be preexisting but exacerbated by a recent workplace injury.

Within a few days of working with Raj to complete the survey in class, we witnessed his father being led out from the family home and business into a waiting police cruiser. In the following weeks and months, we saw the family business go from "closed" to "shut down," and the interior of the business appeared abandoned. One morning, on our way to the school, we saw Raj's father arranging household items and clothing of various sizes to sell on the sidewalk in front of the store. Another morning, he sold shoes and books. On yet another morning, we witnessed the end of an altercation as a police officer led him into the store.

Around this time, Raj's teachers and classmates were in the midst of planning their upcoming graduation, ordering flowers, food, decorations, chairs, and tables for the ceremony, forming setup and cleanup committees, and making decorations in art class. Meanwhile, Raj's teachers, his parents, and representatives of the Children's Aid Society (CAS) 
were discussing whether Raj's father would be permitted to attend his son's graduation ceremony. On the evening of the graduation, we saw his father standing along the wall of the gym with many other parents, videotaping his son receiving his graduation certificate and later accepting a prize. Unbeknownst to us at the time, Raj's father attended the ceremony on the condition that he create no disturbances; his children and their mother were, by this time, under protection of the CAS and living temporarily in a shelter for women and children in the suburbs of Toronto.

\section{Complexities and issues in Raj's experience of multicultural education}

Our purpose in presenting this story of Raj was to examine ways one student's experience might add to the conversation in the field of multicultural education. In reflecting upon what we learned about Raj through participant observations at Bay Street School and interaction with his classmates, teachers, and mother, layers of complexity emerged. We realized the extent to which seemingly unimportant or irrelevant details could be overlooked. Knowledge gained about circumstances of immigration in Raj's family and subsequent settlement into the Bay Street School community underscore the complex task set for students, parents, teachers, and administrators as we attempt to meet the social and academic needs of immigrant and minority students. Many of these difficulties are connected to challenges of identifying and developing programs and practices to meet the needs of a highly diverse group of students.

\subsection{Meeting the language and social needs of ESL students in a school context}

To illustrate the potential complexities of immigration and settlement among students of immigrant and minority background, we highlight the ways that Raj's story of resettlement is very different from that of his sister. Although both indicate Sri Lanka as their country of birth, Raj immigrated to Canada at an earlier age and had the advantage of more time during which to achieve a higher level of oral and written proficiency in English, as well as extensive exposure to this foreign language at a younger age.

English-language proficiency is critical for academic success and integration of immigrant and minority students into North American society. Identifying how best to support ESL learning for students such as Raj and his siblings, however, is complex. Raj himself seemed to have achieved oral fluency in English, but Mr. Jisko commented on his lack of commitment to produce written work and complete assignments. Given that Raj seemed relatively diligent, we wondered whether the lag between the development of oral and written proficiency might be an explanation for his unexpectedly mediocre performance. Cummins (2001) states that "5-7 years [are] required for immigrant students from nonEnglish-speaking backgrounds to come close to grade norms in English academic proficiency" (p. 73), although students "generally develop fluency in conversational aspects of English within a year or two of exposure to the language" (p. 65). Raj may have achieved oral fluency, but he may require a few more years to develop his reading and writing skills to a comparable level. It is likely that Raj's younger brothers would also have achieved native-like oral proficiency in English; since they are 4 and 6 years younger than Raj, they 
had the advantage of earlier, extensive exposure during which to achieve a level of English proficiency comparable to their same-aged Canadian-born peers.

Raj's sister, who is 3 years younger than Raj, however, had not yet achieved English fluency and remained in the ESL Reception Class at the time when we were conducting this research at Bay Street School. In fifth grade at the time, she was moving toward completing elementary schooling as the academic curriculum content set out by the Ministry of Education $(1997,2001)$ was becoming more challenging. Raj's sister spent 2 years in the ESL Reception Class, a policy response designed to help non-English-speaking students successfully enter the Ontario school system. While there are many benefits of intensive language instruction in a classroom specifically designed for ESL learners, Raj's sister found herself lacking opportunities for interaction with native English speakers. As a new immigrant student, she spent much of her time in an ESL classroom that had, in recent years, been dominated by immigrant students from China. Due to the proximity of Bay Street Community School to the largest Chinatown in the Toronto area, many of the ESL students at the school are of Chinese descent. In fact, Chinese students make up $65 \%$ of the total number of students at the school and represent an overwhelming majority in ESL and LEAP ${ }^{2}$ classrooms. The shifting immigration trends led to shifts in the school's catch basin to the point where the dominant culture is not White but Chinese. As a way of illustration, Elaine noted elsewhere that the reference to Multicultural Night in the school has been dubbed Chinese New Year by the students (Chan, 2007).

Moreover, Raj's sister's placement in the ESL Reception Class seemed to further marginalize her from same-aged peers. Not only was she missing the advantage of immersion into an English-speaking school environment to accelerate her acquisition of English proficiency, but membership in this class also limited opportunities to interact with other students of similar ethnic background in mainstream classes.

Raj's family's situation highlights challenges of accommodating for ESL needs of different students, even students from the same families such as Raj and his sister. Reflection upon this situation raises questions about policies and practices currently in place in North American schools where, due to shifting demographics of neighboring communities, dominant cultures among student populations may not necessarily be White cultures or English-speaking. These challenges are further complicated by such factors as immigration history, which in turn contribute to differences in ease of adaptation and adjustment to new school, neighborhood, and family lives after immigration.

Another complexity surfacing through Raj's multicultural education was the role of gender. Certainly, Raj's experience of immigration and resettlement was different from that of his sister. One specific way we see gender issues play out in Raj's story is that while Raj came to Canada with his family, his sister remained in Sri Lanka for an additional 2 years. Raj immigrated at a younger age and with fewer complications in the immigration journey, enabling him to advance through the process of language acquisition and adaptation more quickly and with greater ease than his sister, who started the process later and had more interruptions to her education.

Added to this complexity is the extent of family discontinuity shaping Raj's sister's process of immigration. We described the discontinuity whereby Raj's younger sister was absent from their family life and then reintroduced. Meanwhile, the family underwent 
significant changes in schooling, language, neighborhood community, social status, parental work situation, country of residence, and additional members to the immediate family. Issues of culture, gender, and family circumstance intersect to complicate the process of adaptation for Raj's sister in ways that did not seem as prominent in Raj's experiences of immigration and settlement.

A further complication implicit in Raj's story is the role of poverty in shaping student experience. While we have no direct data on income level, we know through interaction with Raj and his teachers of a loss of employment within the family due to his father's workplace injury. Initial poverty upon immigration and settlement is not uncommon in immigrant communities (Payne, Devol, \& Dreussi Smith, 2001). This relationship between multiculturalism and poverty has far-reaching educational implications for immigrant children and merits further examination. The family's precarious financial situation likely contributed to yet another discontinuity in their Canadian settlement experience-relocation of the family to a women and children's shelter outside his neighborhood community. These numerous discontinuities in Raj's life offer a glimpse of factors that are often overlooked when addressing issues of multicultural education yet are so influential in shaping the education of individual immigrant children.

\section{Policy context: Intersection of identity and multiculturalism as a national agenda}

These factors inform us of the need for practices and policies that are sensitive to the diverse experiences immigrant students may bring to their school contexts. Currently, statements such as the following are included in school board documents outlining equity policies.

The Toronto District School Board values the contribution of all members of our diverse community of students, staff, parents and community groups to our mission and goals. We believe that equity of opportunity, and equity of access to our programs, services and resources are critical to the achievement of successful outcomes for all those whom we serve, and for those who serve our school system.

The Board further recognizes that such inequitable treatment leads to educational, social and career outcomes that do not accurately reflect the abilities, experiences and contributions of our students, our employees, and our parent and community partners. This inequitable treatment limits their future success and prevents them from making a full contribution to society. (Toronto District School Board, 1999)

These school board policies are embedded within a societal context supportive of diversity. For example, it is written in the Canadian Multiculturalism Act that

the Government of Canada recognizes the diversity of Canadians as regards race, national or ethnic origin, colour and religion as a fundamental characteristic of Canadian society and is committed to a policy of multiculturalism designed 
to preserve and enhance the multicultural heritage of Canadians in the economic, social, cultural and political life of Canada. (Minister of State, 1988)

Similarly, in the Canadian Charter of Rights and Freedoms, it is written that,

Every individual is equal before and under the law and has the right to the equal protection and equal benefit of the law without discrimination and, in particular, without discrimination based on race, national or ethnic origin, colour, religion, sex, age or mental or physical disability. (Department of Justice, Canada, Constitution Act, 1982)

Although research and policies provide support for the acknowledgement of diversity in a school context, as illustrated by the existence of and support for policies such as those presented above, there is little known about how multicultural education is experienced in school contexts. More specifically, what does multicultural education look like at the level of a school community, and how it is experienced by individual students, such as Raj, and their families? This examination of Raj's experience of multicultural education highlights discontinuities between existing policies and practices and the lived school experiences of immigrant and minority students in a North American school that need to be included in the multicultural education conversation. Realization of this oversight further emphasizes the power of Schwab's $(1969,1978)$ statement:

Curriculum is brought to bear, not on ideal or abstract representations, but on the real thing, on the concrete case, in all its completeness and with all its differences from all other concrete cases, on a large body of fact concerning which the theoretic abstraction is silent. (Schwab, 1969, 1978, p. 309)

\section{What we learn from Raj's story}

Depending upon the lens through which we gaze, there is much we can learn from this study of one particular student's experiences. Raj's story has educational significance for multicultural education and teacher knowledge. This inquiry speaks to teachers, administrators, and policymakers in diverse communities and informs teacher educators and their students in preparing to work with an increasingly diverse student population.

To begin with, the telling of Raj's story contributes to the field of multicultural education understandings of student experience in a diverse school context and raises questions about the complexities of students' lives. We provide a description of one school context where diversity is embraced, policies are enacted at the national, provincial, and municipal levels to encourage multiculturalism, and children with diverse backgrounds come to know a new culture. This description exposes the challenges children, parents, teachers, and administrators confront in the pursuit of multicultural societies. Understandings gained from this examination point to exigencies immigrant and minority language students face as they negotiate new cultures. 
This focus on developing a comprehensive understanding of one student's experiences lays important groundwork for the development of a teacher knowledge framework built on attention to the particular, as espoused in Schwab's (1969, 1971, 1973, 1978, 1983) work on curriculum. Focusing on children's experience in all their diversity and their complexities balances the reliance upon the theoretical abstractions that often characterize approaches to multicultural education. This approach offers recognition of teacher knowledge and provides a means by which teachers may learn about their students in ways that acknowledge their day-to-day contact with them.

As we worked with teachers to develop and administer the ESL survey, we were struck by the depth and detail of knowledge teachers had of their students and were puzzled by their expressed need for quantitative information to support their rich, narratively constructed knowledge. While there is existing research to substantiate the importance of teacher knowledge expressed through their stories of professional practice (Carter, 1993; Connelly \& Clandinin, 2000; Yonemura, 1982), the teachers with whom we worked needed support to recognize the validity of their knowledge. This research in many ways affirms a way of knowing familiar to many teachers. In this way, another noteworthy feature of this focus on particularity is its consideration of the complexities of student experience upon which teachers may draw to inform their work with students of diverse backgrounds. Furthermore, given the achievement testing era currently shaping education, multicultural education is often not seen as a priority at all levels of influence. As we worked with Raj's teachers at Bay Street School, we saw ways in which pressures to conform to provincial curriculum standards and perform well on standardized grade-level testing created tensions in their work with their students. These tensions were increasingly magnified by budget constraints that limited funding to school-based programs directly related to enhancing school performance on these standardized tests. In fact, the ESL survey described here was a means for the teachers to gather information about the needs of their ESL students and gain resources for them.

This work of teachers involved in the ESL Workgroup was supported by their school principal, who saw the survey as a means of informing school board officials of the need for financial support for ESL resources. While this particular administrator supported and lobbied for the resources to meet the needs of students and parents in his school, this is not always the case. Typically, courses in the field of educational leadership seem to focus more on aspects such as change, professional development and supervision, and administrative theory, while overlooking the need for courses addressing the impact of increasing diversity. Understanding and acknowledging tensions experienced by students, families, and teachers, however, is central to the work of administrators in diverse school communities. This work substantiates the contribution of student narratives and illustrates the importance of attention to the particulars of individual students' lives. Including multicultural education in educational leadership programs, in addition to curriculum and teacher education programs, is critical if policymakers and administrators hope to address the academic performance and success of increasingly diverse school populations.

Regarding contributions to the fields of multicultural education and teacher knowledge, this research attends to tensions teachers and administrators sometimes face in balancing detailed knowledge of their students' lives with professional responsibilities. Examination 
of Raj's stories reveals the knotted and tangled ball of expectations - the threads of family, school, peer, and social influences inherent to diverse school and cultural contexts as experienced by individual students - and stresses the importance of understanding particularities and specifics and the role of policies in shaping these contexts. Embracing Schwab's notion of curriculum as constituted of particularities promotes a focus on the needs of diverse students. This research also contributes to the knowledge of teachers, teacher education students, and informs teacher education programs. Through learning about the experiences of Raj's school and home life, teachers may glean a picture of various aspects of an individual student's school and home life in interconnected ways. From a teacher's perspective, there are many challenges to meeting the needs of students such as Raj and his siblings, especially given their difficult social circumstances and different academic needs. Learning about individual student's experiences of immigration and settlement and the impact upon their ESL acquisition, and overall adjustment to school in a new culture, contributes to a body of knowledge upon which teachers may draw as they work with their students of diverse backgrounds. These stories contribute to a more detailed understanding of some of the struggles an immigrant or minority student may encounter in a new community.

Raj's story is presented through the lens of the particular. Particularity as a curricular concept is important for teacher education candidates as they prepare to meet the challenges of a diverse society. This approach is a shift to broaden the abstract and include the concrete; it is a means of offsetting the tendency of researchers to draw upon theoretical solutions for real-life problems and prepares candidates to focus on individual children. Particularity brings a Schwabian sense into the curriculum conversation. This language of particularity highlights for teacher candidates the complexity of curricular challenges encountered by teachers as they work with diverse student populations. In this way, the stories have the potential to broaden the experiences of teacher candidates and enhance possibilities for the development and expression of empathy and compassion.

Stories like Raj's broaden teacher candidates' experiences by drawing upon the experiences of individual students as a resource for developing appropriate curriculum. Of particular importance is an appreciation for ways in which a focus on particular stories exposes and challenges dominant stories of teacher education that still seem to be focused on generalized knowledge about minority or immigrant students. Narratives such as Raj's highlight the complex realities students may experience as they compose their identities and lives in school. In a milieu increasingly shaped by standardization, attending to the narratives of individual students and their families is a reminder of the dangers of smoothing out these complexities, a reminder not to lose sight of the diversity involved, and a reminder of the need for sustained attention to issues of social justice and equity in education. 


\section{Notes}

1. Similar to other students and staff at Bay Street School, when Raj speaks of "being in ESL," he is referring to the English-as-a-Second-Language Reception Class established in the school to help students arriving from outside Canada with limited, or no, proficiency in English to transition into mainstream classrooms with same-aged peers. The ESL Reception Class is located in Room 26 with Ms. March as their teacher.

2. Learning Enrichment Academic Programs (LEAPs) are run through the Toronto District School Board to help students who have had gaps in their education to quickly achieve English fluency and to catch up to their same-aged peers in subject matter content. Many of the ESL students moved from ESL Reception Class to the LEAP classroom before they were integrated on a fulltime basis into classrooms with their same-age peers.

\section{References}

Ada, A. F. (1988). The Pajaro Valley experience: Working with Spanish-speaking parents to develop children's reading and writing skills in the home through the use of children's literature. In T. Skutnabb-Kangas, \& J. Cummins (Eds.), Minority education: From shame to struggle. Clevedon, England: Multilingual Matters.

Banks, J. A. (1995). Multicultural education: Its effects on students' racial and gender role attitudes. In J. A. Banks, \& C. A. McGee Banks (Eds.), Handbook of research on multicultural education (pp. 617-627). Toronto: Prentice-Hall International.

Carger, C. L. (1996). Of borders and dreams: A Mexican-American experience of urban education. New York: Teachers College Press.

Carter, K. (1993). The place of story in the study of teaching and teacher education. Educational Researcher, 22, 5-12, 18.

Chan, E. (2006). Teacher experiences of culture in the curriculum. Journal of Curriculum Studies, 38(2), 161-176.

Chan, E. (2007). Student experiences of a culturally-sensitive curriculum: Ethnic identity development amid conflicting stories to live by. Journal of Curriculum Studies, 39(2), 177-194.

Chan, E., \& Ross, V. (2002). Report on the ESL Survey Sponsored by the ESL Workgroup in collaboration with the OISE/UT Narrative and Diversity Research Team. Toronto: Centre for Teacher Development, Ontario Institute for Studies in Education of the University of Toronto.

Clandinin, D. J. (1986). Classroom practice: Teacher images in action. Barcombe Lewes: Falmer Press.

Connelly, F. M., \& Clandinin, D. J. (1988). Teachers as curriculum planners: Narratives of experience. New York: Teachers College Press, Columbia.

Clandinin, D. J., \& Connelly, F. M. (1992). Teacher as curriculum maker. In P. W. Jackson (Ed.), Handbook of research on curriculum (pp. 363-401). New York: Macmillan.

Clandinin, D. J., \& Connelly, F. M. (1994). Personal experience methods. In N. K. Denzin, \& Y. S. Lincoln (Eds.), Handbook of qualitative research in the social sciences (pp. 413-427). Thousand Oaks, CA: Sage Publications.

Clandinin, D. J., \& Connelly, F. M. (2000). Narrative inquiry: Experience and story in qualitative research. San Francisco: Jossey-Bass Publishers.

Clandinin, D. J., Huber, J., Huber, M., Murphy, M. S., Murray Orr, A., Pearce, M., \& Steeves, P. (2006). Composing diverse identities: Narrative inquiries into the interwoven lives of children and teachers. New York: Routledge. 
Connelly, F. M., \& Clandinin, D. J. (1994). Telling teaching stories. Teacher Education Quarterly, 21, 145-158.

Connelly, F. M., \& Clandinin, D. J. (2000). Narrative understandings of teacher knowledge. Journal of Curriculum and Supervision, 15, 315-331.

Connelly, F. M., He, M. F., Phillion, J., Chan, E., \& Xu, S. (2004). Bay Street School: Where you belong. Orbit, 34(3), 39-42.

Connelly, F. M., Phillion, J., \& He, M. F. (2003). An exploration of narrative inquiry into multiculturalism in education: Reflecting on two decades of research in an inner-city Canadian community school. Curriculum Inquiry, 33(4), 363-384.

Craig, C. (1995). Knowledge communities: A way of making sense of how beginning teachers come to know. Curriculum Inquiry, 25(2), 151-172.

Craig, C. (2003a). Narrative inquiries of school reform: Storied lives, storied landscapes, storied metaphors. Greenwich, CT: Information Age Publishing.

Craig, C. (2003b). School portfolio development: A teacher knowledge approach. Journal of Teacher Education, 54(2), 122-134.

Craig, C. (2003c). What teachers come to know through school portfolio development. Teaching and Teacher Education, 19(8), 815-827.

Craig, C. (2004). Shifting boundaries on the professional knowledge landscape: When teacher communications become less safe. Curriculum Inquiry, 34(4), 395-423.

Craig, C. (2006a). Why is dissemination so difficult? The nature of teacher knowledge and the spread of school reform. American Educational Research Journal, 43(2), 257-293.

Craig, C. (2006b). Change, changing, and being changed: A self-study of a teacher educator's becoming real in the throes of urban school reform. Studying Teacher Education, 2(1), 105-116.

Craig, C. J., \& Ross, V. (2007). The development of the image of teachers as curriculum makers. In F. M. Connelly, M. F. He, \& J. Phillion (Eds.), Handbook of curriculum and instruction (pp. 282-305). Thousand Oaks, CA: Sage Publications.

Cummins, J. (1996). Negotiating identities: Education for empowerment in a diverse society. Ontario, CA: CABE (California Association for Bilingual Education).

Cummins, J. (2001). Negotiating identities: Education for empowerment in a diverse society (2nd ed.). Los Angeles, CA: California Association for Bilingual Education.

Department of Justice, Canada (1982). Constitution Act (1982) Canadian Charter of Rights and Freedoms. http://laws.justice.gc.ca/en/charter/ index.html (visited November 9, 2004)

Dewey, J. (1916). Democracy and education: An introduction to the philosophy of education. New York: The Free Press.

Dewey, J. (1938). Experience and education. New York: Simon \& Schuster.

Gay, G. (2000). Culturally responsive teaching: Theory, research, E practice. New York: Teachers College Press.

He, M. F., Phillion, J., \& Roberge, B. (1999). Narrative understanding of bilingualism: A review of language, culture and power: Bilingual families and the struggle for quality education. Curriculum Inquiry, 29, 447-457.

Huber, J., Murphy, M. S., \& Clandinin, D. J. (2003). Creating communities of cultural imagination: Negotiating a curriculum of diversity. Curriculum Inquiry, 33(4), 343-362.

Huber, J., \& Whelan, K. K. (2001). Living, telling, and retelling stories to live by: Negotiating the multiplicity of self across shifting landscapes. Journal of Critical Inquiry into Curriculum and Instruction, 3(2), 28-35. 
Igoa, C. (1995). The inner world of the immigrant child. New York: St. Martin's Press.

Jackson, P. (1990). Life in classrooms. New York: Teachers College Press.

Kouritzin, S. G. (1999). Face(t)s of first language loss. Mahwah, NJ: Lawrence Erlbaum Associates, Publishers.

Ladson-Billings, G. (1995). Multicultural teacher education: Research, practice, and policy. In J. A. Banks, \& C. A. McGee Banks (Eds.), Handbook of research on multicultural education (pp. 747-759). Toronto: Prentice-Hall International.

Ladson-Billings, G. (2001). Crossing over to Canaan: The journey of new teachers in diverse classrooms. San Francisco: Jossey-Bass.

McCaleb, S. P. (1994). Building communities of learners: A collaboration among teachers, students, families and community. New York: St. Martin's Press.

Minister of State (Multiculturalism) (1988). Canadian Multiculturalism Act. http://www.pch.gc.ca/ progs/multi/policy/act_e.cfm (visited November 4, 2004)

Ministry of Education and Training, Ontario. (1997). The Ontario curriculum, grades 1-8. Language, 1997. Toronto: Ministry of Education and Training.

Ministry of Education and Training, Ontario. (2001). The Ontario curriculum, grades 1-8. English as a second language and English literacy development: A resource guide. Toronto: Ministry of Education and Training.

Moodley, K. A. (1995). Multicultural education in Canada: Historical development and current status. In J. A. Banks, \& C. A. McGee Banks (Eds.), Handbook of research on multicultural education (pp. 801-820). Toronto: Prentice-Hall International.

Payne, R., Devol, P., \& Dreussi Smith, T. (2001). Bridges out of poverty: Strategies for professionals and communities. Highlands, TX: Process, Inc. Publishing.

Phillion, J., He, M. F., \& Connelly, F. M. (2005). Narrative and experience in multicultural education. Thousand Oaks, CA: Sage Publishing.

Rodriguez, R. (1982). Hunger of memory: The education of Richard Rodriguez. Boston, MA: David R. Godine, Publisher, Inc.

Ross, V. (2003). Walking around the curriculum tree: An analysis of a third/fourth-grade mathematics lesson. Journal of Curriculum Studies, 35(5), 567-584.

Ross, V. (2004). A story of reform: Math, science, technology investigation (MSI) in room 34 at Bay Street Community School. Journal of Curriculum Studies, 36(5), 587-594.

Schwab, J. J. (1969). The practical: A language for curriculum. School Review, 78, 1-23.

Schwab, J. J. (1971). The practical: Arts of eclectic. School Review, 79, 493-542.

Schwab, J. J. (1973). The practical 3: Translation into curriculum. School Review, 81, 501-522.

Schwab, J. J. (1978). Science, curriculum and liberal education: Selected essays. Chicago: The University of Chicago Press (see Westbury \& Wilkof, 1978).

Schwab, J. J. (1983). The practical 4: Something for curriculum professors to do. Curriculum Inquiry, 13, 239-265.

Statistics Canada (1998). 1996 Census: Ethnic origin, visible minorities. http://www.statcan.ca/Daily/ English/980217/d980217.html (visited July 31, 2002)

Statistics Canada (2001). Widest linguistic diversity found in Toronto. The Globe and Mail, December 11, 2002, A7.

Statistics Canada (2003a). Canada's ethnocultural portrait: The changing mosaic. http://www.statcan .ca/Daily/English/030121/td030121.htm (visited January 21, 2003) 
Statistics Canada (2003b). Census of population: Immigration, birthplace and birthplace of parents, citizenship, ethnic origin, visible minorities and Aboriginal peoples. http://www.statcan.ca/Daily/ English/030121/d030121a.htm (visited January 23, 2003)

Toronto District School Board (1999). Equity foundation statement. http://www.tdsb.on.ca/_site/ ViewItem.asp?siteid $=15 \&$ menuid $=684 \&$ pageid $=548$ (visited November 17,2005 )

United Nations Development Programme (2004a). Summary: Human development report 2004: Cultural liberty in today's diverse world. http://old.undp.bg/user_files/en/documents/publications/ hdr/2004/ghdr04_summary.pdf (visited November 20, 2006)

United Nations Development Programme (2004b). Demographics of Toronto, from Wikipedia, the free encyclopedia. http://en.wikipedia.org/wiki/Demographics_of_Toronto (visited November 20, 2006)

Villegas, A. M. (1991). Culturally responsive pedagogy for the 1990s and beyond. Princeton, NJ: Educational Testing Service.

Westbury, I., \& Wilkof, N. J. (Eds.). (1978). Science, curriculum, and liberal education: Selected essays. Chicago: The University of Chicago Press (see Schwab, 1978).

Wong-Fillmore, L. (1991). When learning a second language means losing the first. Early Childhood Research Quarterly, 6, 323-346.

Yonemura, M. V. (1982). Teacher conversations: A potential source of their own professional growth. Curriculum Inquiry, 12, 239-256. 